\title{
O cuidado Ético quando se trata de publicações acadêmicas
}

Gislene Farias de Oliveira ${ }^{1}$

Resumo: A cada dia, num mundo com a riqueza tecnológica que se tem, carece e demanda por reflexões éticas, relativas às novas práticas. O objetivo deste editorial é discutir alguns aspectos éticos, bem como morais e legais, associados às publicações cientificas. A garantia do respeito às pessoa, bem como às normativas metodológicas associadas aos trabalhos acadêmicos e científicos, são normalmente, elementos que cabem ao pesquisador principal. Daí , nota-se a grande responsabilidade do editor, pois este responde, conjuntamente com os avaliadores, pela ética nas publicações de um periódico científico, de forma que as informações nele contidas reflitam a veracidade dos fatos, portanto sendo digno da confiança da comunidade científica e da sociedade de uma maneira geral, prestando-se como referência para tomadas de decisões.

Palavras-chave: Ética, publicações acadêmicas, editor científico.

\section{The Ethics when it comes to Academic Publications}

\begin{abstract}
Every day, in a world with the technological wealth that one has, it lacks and demand for ethical reflections, relative to the new practices. The purpose of this editorial is to discuss some ethical as well as moral and legal aspects associated with scientific publications. The guarantee of respect for the person, as well as the methodological norms associated with academic and scientific work, are usually elements that belong to the principal investigator. Hence the great responsibility of the editor, who responds, together with the evaluators, for the ethics in the publications of a scientific journal, so that the information contained in it reflects the truthfulness of the facts, therefore being worthy of the confidence of the scientific community and society in general, providing as a reference for decision-making.
\end{abstract}

Keywords: Ethics, academic publications, scientific editor.

\section{Introdução}

A ética enquanto terminologia, envolve uma série de reflexões sobre as diversas formas possíveis de relações entre as pessoas, suas crenças e valores. Está em todas as atividades humanas, onde se possa pensar em certo e errado, em bem ou mal, em ações consideradas positivas ou negativas.

\footnotetext{
${ }^{1}$ Psicóloga, Doutora em Psicologia social. Pós-doutorado em Ciências da saúde. Professora da Faculdade de Medicina da Universidade Federal do Cariri. Contato: gislenefarias@gmail.com.
} 
A ética deve reger todos os campos da atividade humana, seja na política, nas organizações, na economia, na medicina, no jornalismo e, nas publicações científicas. Um tema de grande repercussão é a bioética. Uma ética dirigida especificamente para as áreas das Ciências da saúde e da vida. A ética é diferente da moral, por ser universal e permanente, enquanto a moral, é uma conduta temporária e mutável.

Não vamos discutir todos os aspectos que envolvem a filosofia da ética, pois é bastante vasto e variável, além do mais já é um tema extensamente explorado em publicações diversas. Como a Id on Line Revista Muitidisciplinar e de Psicologia, é um periódico muito procurado pela comunidade científica, nesta reflexão objetivamos levar aos nossos leitores, autores e revisores, algumas questões importantes, relacionadas com a ética nas publicações científicas.

Como não se trata de um tema inédito. É provável que alguns editores de periódicos científicos certamente já foram confrontados com situações diversas envolvendo a ética (MUCCIOLI et al., 2006).

Rodrigues, Crespo e Miranda (2006) tem destacado os malefícios que as fraudes tendem a causar algumas irregularidades que a ética condena, tais como: apresentação prematura de resultados, fraude; mentira; desonestidade; omissão; adulteração; deturpação ou violação, encontrados em muitos artigos com resultados falseados, duvidosos ou distorcidos, que levam a alterações nos rumos das pesquisas, comprometendo seriamente experimentos, de maneira irresponsável.

Vê-se daí que são muitas as possibilidades éticas que envolvem esta temática. Sobre isso, alguns periódicos passaram a criar regras próprias (ethical guidelines). Mesmo assim, tais procedimentos não parecem ser garantia de evitar-se tais episódios. Esses certamente dependem de uma consciência madura e da idoneidade daqueles que lidam om a ciência.

Outra questão importante é sobre a colaboração e a co-autoria. Estas precisam estarem devidamente resolvida e esclarecida entre os autores, antes de iniciar-se o processo de submissão do artigo. Portanto, todos os autores precisam assinar um termo concordando com o exposto na publicação. É de competência do autor principal, a guarda deste e de outros documentos que se façam necessários.

Não se deve indicar como co-autor, aquele que tenha pouca ou nenhuma participação na publicação. Aqueles manuscritos oriundos de teses, dissertações e monografias, carecem do aceite do orientador. É situação desagradável, para um editor, receber reclamações de coautores que afirmam "desconhecer o trabalho"; ou não ter sido consultado sobre tal. De forma 
semelhante e não menos nociva é a omissão de qualquer participante do processo da pesquisa, que tenha efetivamente contribuído com o trabalho submetido.

Os agradecimentos nem sempre se limitam aos financiadores. Podem e devem incluir aqueles colaboradores que, de alguma maneira, participaram para o desfecho final do trabalho. No entanto, é preciso obter sua concordância sobre a inclusão do seu nome.

As citações em um artigo científico são de grande relevância. Tanto ajudam a compor o Fator de Impacto de um jornal, como saber a relevância que um determinado artigo tem para os autores, pelo número de citações que o mesmo agrega. Portanto, nas revisões de literatura, bem como nas referências, espera-se que os autores possam citar, de maneira correta os trabalhos que ajudaram a compor o conjunto de ideias discutidas no artigo. A omissão de estudos, além de comprometer a qualidade do artigo, sem o registro adequado e obrigatório da fonte, configura-se como plágio.

Trabalhos submetidos com tais características, são de total responsabilidade dos autores. Os avaliadores, em geral, são pessoas da confiança do editor ou de seus pares profissionais, com total liberdade de acatar ou rejeitar material incompleto ou considerados impróprios para publicação.

Os manuscritos precisam ser material de pesquisa inédita, a não ser que sejam de revisão da literatura. Portanto, a manipulação ou supressão de informações ou dados, burla de qualquer espécie nas publicações configuram fraude, assim como todos os outros aspectos salientados, a saber: publicação de trabalhos obtido de experimentos não aprovados por comitê de ética, publicações sem consentimento de um dos autores, omissão de algum dos autores, as publicações que contenham plágio, ou divulgar dados confidenciais sem a devida autorização são consideradas graves faltas éticas.

Infelizmente, muitos casos têm sido revelados envolvendo falta ética em publicações científicas. Há um endereço do Committee on Publication Ethics, disponível em $<$ http://www.publicationethics.org.uk/>, onde se pode verificar tais situações e compreender o quão grave é esta problemática.

A adoção do registro DOI - Digital Object Identifier, adotado já há algum tempo pela Id on Line Revista Multidisciplinar e de Psicologia, é uma ferramenta que ajuda os autores a protegerem suas produções acadêmicas. Esta permite um referencial cronológico, fundamental para evitar-se o plágio. 
Enfim, o que vai importar no final, além da consciência dos autores é a consistência e inovação do material produzido, dentro dos padrões metodológicos e, respeitando-se os resguardos éticos. Dessa forma, a contribuição torna-se genuína, favorecendo, não apenas os seus autores, mas toda a sociedade que de tal informação demanda.

\section{Referências}

MUCCIOLI, C.; CAMPOS, M.; GOLDCHMIT, M.; DANTAS, P. E. C.; BECHARA, S. J.; COSTA, V. P.; Editorial, Arq. Bras. Oftalmol. 2006, 69, 787.

RODRIGUES, A. V. F.; CRESPO, I. M.; MIRANDA, C. L.; Em Questão, 2006, 12, 33.

\section{Como citar este artigo (Formato ABNT):}

OLIVEIRA, Gislene Farias de. de. O cuidado Ético quando se trata de publicações acadêmicas. Id on Line Revista Multidisciplinar e de Psicologia, 2018, vol.12, n.40, p.897-900. ISSN: 19811179 .

Recebido: 14.05 .2018

Aceito: 18.05 .2018 